\title{
Quantificação da ferrugem asiática e aspectos nutricionais de soja suprida com silício em solução nutritiva
}

\author{
Luciana Maria de Lima ${ }^{1}$, Edson Ampélio Pozza ${ }^{1}$, Adélia Aziz Alexandre Pozza², Thiago Antônio de Pádua Silva \\ Fonseca $^{3}$, Janice Guedes de Carvalho ${ }^{2}$
}

${ }^{1}$ Departamento de Fitopatologia, ${ }^{2}$ Departamento de Ciência do Solo e ${ }^{3}$ Departamento de Engenharia Agrícola, Universidade Federal de Lavras, Cx. Postal 3037, CEP 37200-000, Lavras-MG. *Parte da Dissertação de Mestrado da primeira autora. Universidade Federal de Lavras. 2005. Autor para correspondência: Edson Ampélio Pozza. (eapozza@ufla.br )

Data de chegada: 22/06/2008. Aceito para publicação em: 31/08/2009.

\section{RESUMO}

Lima, L.M.; Pozza, E.A.; Pozza, A. A. A.; Fonseca, T. A. P. S.; Carvalho, J. G. Quantificação da ferrugem asiática e aspectos nutricionais de soja suprida com silício em solução nutritiva. Summa Phytopathologica, v.36, n.1, p.51-56, 2010.

Para quantificar a severidade da ferrugem, os teores de clorofilas $a$ e $b$ e os carotenóides e também a nutrição em plantas de soja supridas com silício, implantou-se um experimento em blocos casualizados com 6 tratamentos e 4 repetições. Os tratamentos consistiram em doses de silicato de potássio $(0 \mathrm{mg} / \mathrm{L}, 56 \mathrm{mg} / \mathrm{L}, 112$ $\mathrm{mg} / \mathrm{L}, 168 \mathrm{mg} / \mathrm{L}, 224 \mathrm{mg} / \mathrm{L}$ e $280 \mathrm{mg} / \mathrm{L}$ ). As plantas foram inoculadas no estádio V4. Nove dias após a inoculação, iniciaram-se as avaliações semanais do número de lesões de ferrugem da $s o j a / \mathrm{cm}^{2}$ de área foliar, no total de cinco. Ao final do experimento, os dados foram integrados ao longo do tempo, obtendo-se a área abaixo da curva do número de lesões $/ \mathrm{cm}^{2}$ (AACNL). Após o término das avaliações, determinou-se a quantidade de clorofilas $a$ e $b$, carotenóides e lignina das folhas das plantas de soja com as doses crescentes de silício. Os teores de macro e micronutrientes da parte aérea das plantas também foram analisados. Observou-se redução da AACNL com aumento das doses de silício na solução nutritiva. A AACNL reduziu, enquanto que os teores de fósforo, cálcio, enxofre e zinco, de clorofila $b$, carotenóides e lignina, na parte aérea, aumentaram com a adição de silício.

Palavras-chave adicionais: silicato de potássio, Glycine max, Phakopsora pachyrhizi.

\section{ABSTRACT}

Lima, L.M.; Pozza, E.A.; Pozza, A. A. A.; Fonseca, T. A. P. S.; Carvalho, J. G. Quantification of Asian rust and nutritional aspects of soybean due to the use of silicon supplied via nutrient solution. Summa Phytopathologica, v.36, n.1, p.51-56, 2010.

Aiming to quantify the severity of Asian rust, the content of the chlorophylls $a$ and $b$ and carotenoids as well some nutritional aspects of soybean plants supplied with silicon in the form of soluble potassium silicate solution an experiment was carried out in a random block design with 6 treatments and four replicates. Treatments comprised potassium six silicate doses $(0 \mathrm{mg} / \mathrm{L}, 56$ $\mathrm{mg} / \mathrm{L}, 112 \mathrm{mg} / \mathrm{L}, 168 \mathrm{mg} / \mathrm{L}, 224 \mathrm{mg} / \mathrm{L}$ and $280 \mathrm{mg} / \mathrm{L}$ ). Plants were inoculated at the V4 stage and evaluated for rust severity five times starting at the 9 th day after inoculation weekly. The severity data were integrated with time obtaining the area under the number lesions progress curve (AUNLC). At the end of experiment, shoots from plants that received increasing silicon doses were sampled in order to analyze the chlorophyll $a$ and $b$, carotenoids, lignin, macro and micronutrients. Adding silicon reduced AUNLC and increase the level of chlorophyll $b$, carotenoids, lignin, $\mathrm{P}, \mathrm{Ca}, \mathrm{S}$ and $\mathrm{Zn}$ in soybean plants.

Keywords: Potassium silicate, Glycine max, Phakopsora pachyrhizi.

Um dos principais fatores limitantes à maior produtividade da soja (Glycine max L.) são as doenças. Atualmente, a ferrugem asiática, cujo agente etiológico é o fungo Phakopsora pachyrhizi H. Sydow \& P. Sydow destaca-se por aumentar significativamente os custos de produção, devido à necessidade de várias pulverizações com fungicidas por ser, até o momento, a única medida de controle eficiente. O silício, apesar de não ser considerado elemento essencial, proporciona benefícios a várias espécies vegetais, incluindo redução da severidade de doenças em inúmeras culturas $(4,6,12,23)$. Entretanto, ainda é pequeno o conhecimento do efeito do silício na ferrugem asiática e seu metabolismo na cultura da soja. Plantas de trigo tratadas com silício aumentaram a atividade fotossintética e também os teores de clorofila $a, b, a+b$ e carotenóides (10). Adatia \& Besford (1) também relataram aumento no teor de clorofila e da atividade da ribulose bi-fosfato carboxilase em plantas de pepino, cultivados em solução nutritiva com Si. Segundo Marschner (17), os mecanismos de defesa potencializados pelo silício incluem acúmulo de lignina, fitoalexinas, compostos fenólicos, quitinases e peroxidases.

Muitos desses estudos com silício e doenças de plantas foram realizados em solução nutritiva, sendo a primeira etapa para o entendimento dos processos fisiológicos envolvidos na relação patógeno hospedeiro $(1,12,20)$. Nessas condições, foi possível isolar o efeito de outros fatores e com isso tornar evidente a contribuição do silício na redução da intensidade da doença. Assim, o cultivo da soja nessas condições, utilizando fonte solúvel como silicato de potássio, possibilitou o estudo dessa interação. $\mathrm{O}$ conhecimento do efeito do 
silício sobre a suscetibilidade da soja à ferrugem pode contribuir no manejo dessa doença.

Este trabalho teve como objetivos quantificar a severidade da ferrugem, os teores de clorofilas $a$ e $b$ e os carotenóides e também a nutrição em plantas de soja supridas com silício.

\section{MATERIAL E MÉTODOS}

O experimento foi implantado em casa-de-vegetação do Departamento de Fitopatologia da Universidade Federal de Lavras. A semeadura da soja, cultivar MG/ BR 46 (Conquista) foi realizada em bandejas de isopor contendo vermiculita. Após a emergência, as plântulas foram transferidas para bandejas com 10 litros de solução básica de Hoagland \& Arnon (11), a 20\% da força iônica e sob aeração contínua por 15 dias. Após esse período, as mudas foram transferidas para recipientes plásticos com capacidade para 5,5 litros contendo a solução de Hoagland \& Arnon completa com os tratamentos (Tabela 1), recebendo aeração constante promovida por compressor. $\mathrm{O}$ delineamento experimental foi em blocos casualizados, sendo cada recipiente plástico, com duas plantas, considerado uma unidade experimental. Os tratamentos consistiram de $0 \mathrm{mg} / \mathrm{L}, 56 \mathrm{mg} / \mathrm{L}, 112$ $\mathrm{mg} / \mathrm{L}, 168 \mathrm{mg} / \mathrm{L}, 224 \mathrm{mg} / \mathrm{L}$ e $280 \mathrm{mg} / \mathrm{L}$ de silício, na forma de silicato de potássio e quatro repetições. O potássio foi equilibrado na solução, de maneira a se obter a mesma concentração em todos os tratamentos (Tabela 1). Monitorou-se o pH da solução mantendo-o entre 5,0 e 5,5 com a adição de $\mathrm{HCl} 0,1 \mathrm{~mol} / \mathrm{L}$ ou $\mathrm{NaOH} 0,1 \mathrm{~mol} / \mathrm{L}$. Quando necessário, o volume dos vasos foi completado com água destilada. A troca da solução nutritiva foi realizada nos diferentes tratamentos, quando a condutividade elétrica atingiu $30 \%$ do valor inicial.

Tabela 1. Volume de solução estoque $(\mathrm{mL} / \mathrm{L})$ necessário para a elaboração dos tratamentos com as concentrações de silício na solução nutritiva.

\begin{tabular}{|c|c|c|c|c|c|c|}
\hline \multirow{2}{*}{$\begin{array}{l}\text { Soluções estoque } \\
\mathrm{Ca}\left(\mathrm{NO}_{3}\right)_{2} \cdot 4 \mathrm{H}_{2} \mathrm{O}-[1 \mathrm{~mol} / \mathrm{L}]\end{array}$} & \multicolumn{6}{|c|}{$\begin{array}{c}\text { Concentrações de silício na } \\
\text { solução nutritiva }(\mathrm{mg} / \mathrm{L})\end{array}$} \\
\hline & 5 & 5 & 5 & 5 & 5 & 5 \\
\hline $\mathrm{KNO}_{3}-[1 \mathrm{~mol} / \mathrm{L}]$ & 5 & 4 & 3 & 2 & 1 & - \\
\hline $\mathrm{MgSO}_{4} .7 \mathrm{H} \mathrm{O}-[1 \mathrm{~mol} / \mathrm{L}]$ & 2 & 2 & 2 & 2 & 2 & 2 \\
\hline $\mathrm{NH} \mathrm{H} \mathrm{PO}_{4}-[1 \mathrm{~mol} / \mathrm{L}]$ & 0 & 0,5 & 0,4 & 0,6 & 0,8 & 1 \\
\hline $\mathrm{KH}_{2} \mathrm{PO}_{4}-[1 \mathrm{~mol} / \mathrm{L}]$ & 1 & 0,8 & 0,6 & 0,4 & 0,2 & - \\
\hline Silicato Potássio - [202,6 mL/l] & - & 0,45 & 0,9 & 1,36 & 1,81 & 2,26 \\
\hline $\mathrm{NH} \mathrm{NO}_{4}-[1 \mathrm{~mol} / \mathrm{L}]$ & - & 0,5 & 1,0 & 1,5 & 2,0 & 2,5 \\
\hline Micro & 1 & 1 & 1 & 1 & 1 & 1 \\
\hline $\mathrm{Fe}_{\mathrm{EDTA}}{ }^{2}$ & 1 & 1 & 1 & 1 & 1 & 1 \\
\hline
\end{tabular}

${ }^{1}$ Solução coquetel completa de micronutrientes: dissolveram-se separadamente $2,86 \mathrm{~g}$ $\mathrm{H} \mathrm{BO} ; 1,81 \mathrm{~g} \mathrm{MnCl} .4 \mathrm{H} \mathrm{O} ; 0,22 \mathrm{~g} \mathrm{ZnSO} .7 \mathrm{H} \mathrm{O} ; 0,08 \mathrm{~g} \mathrm{CuSO} .5 \mathrm{H} \mathrm{O}$ e $0,02 \mathrm{~g}$ $\mathrm{H}^{3} \mathrm{MoO}$. $\mathrm{H} \mathrm{O}$ e, após misturâ, completou-se o volum² para $1000 \mathrm{~mL}{ }^{4}$

${ }^{2}$ Š̉oluçẫo Fe-EDTA: (a) Solução A - 33,3 g de Na -EDTA dissolvidos em $500 \mathrm{~mL}$ de água destilada a $30^{\circ} \mathrm{C}$ contendo $100,4 \mathrm{~mL}$ de NaOH 1 mol$/ 2 \mathrm{~L}$; (b) Solução B - 24,9 g de FeSO .7H O dissolvida em $300 \mathrm{~mL}$ de água destilada a $70^{\circ} \mathrm{C}$, contendo $4 \mathrm{~mL}$ de $\mathrm{HCl} 1 \mathrm{~mol} / \mathrm{L}$; misturaramse as soluções A e B, completou-se o volume para $1000 \mathrm{~mL}$ com água destilada e coloca sob aeração constante por 12 horas. A solução foi acondicionada em vasilhames âmbar recobertos por papel alumínio para a proteção contra a luz.

Quando as plantas atingiram o estádio V4, foram inoculadas com suspensão de $2 \times 10^{4}$ urediniósporos $/ \mathrm{mL}$ na face abaxial do terceiro trifólio de cada planta. Em seguida foram cobertas com saco plástico por $12 \mathrm{~h}$ para manter a umidade nas folhas. Após a retirada da câmara úmida, as plantas foram mantidas em casa-devegetação com umidade próxima a $100 \%$, controlada por nebulizador, para favorecer a germinação e a penetração do patógeno e consequentemente os ciclos secundários. A temperatura e a umidade relativa do ar dentro da casa-de-vegetação foram monitoradas durante toda condução do experimento com termohigrógrafo.

A quantificação da doença teve início com aparecimento dos primeiros sintomas da ferrugem (estádio V6). Foram realizadas cinco avaliações, com intervalo semanal, do número de lesões $/ \mathrm{cm}^{2}$ de área foliar realizada nos folíolos centrais do terceiro e quarto trifólio de cada planta. Os folíolos foram marcados com caneta de tinta permanente fazendo-se um quadrado de $1 \mathrm{~cm}^{2}$ de área, em cada lado do limbo foliar totalizando quatro quadrados por planta. O número de lesões $/ \mathrm{cm}^{2}$ foi calculado pela média das amostragens (29). Após cinco avaliações, calculou-se a área abaixo da curva de progresso do número de lesões $/ \mathrm{cm}^{2}$ em cada tratamento (26).

No estádio R1, o sexto trifólio de cada tratamento foi coletado e armazenado em freezer, a $-20^{\circ} \mathrm{C}$, até o procedimento de determinação de clorofila $a, b$, carotenóides e lignina. Desse material vegetal, 0,2 gramas de tecidos foliares foram macerados, em almofariz, com nitrogênio líquido e extraídos em acetona $85 \%$, por 24 horas, na ausência de luz. Em seguida, o material foi centrifugado a $8000 \mathrm{rpm}$ por $15 \mathrm{~min}$ e o sobrenadante foi utilizado para determinar o conteúdo de clorofila $a, b$ e de carotenóides nas absorbâncias A664nm, A647nm e A455nm (28) de acordo com as seguintes equações:

Clorofila $a=\left(13,7 \times\right.$ Abs $\left._{664 \mathrm{~nm}}\right)-\left(5,76 \mathrm{x} \mathrm{Abs}_{647 \mathrm{~nm}}\right)$

Clorofila $b=\left(25,80 \times \mathrm{Abs}_{647 \mathrm{~nm}}\right)-\left(7,60 \mathrm{x} \mathrm{Abs}_{664 \mathrm{~nm}}\right)$

Carotenóides $=\left(4,75 \mathrm{x} \mathrm{Abs}_{455 \mathrm{~nm}}\right)-((\mathrm{Chl} a+\mathrm{Chl} b) \times 0,226$.

Para determinar o conteúdo de lignina, utilizou-se a metodologia do experimento com tioglicólico, em que 0,2 gramas de tecidos foliares foram macerados em almofariz e incubados, por $24 \mathrm{~h}$, em solução acetona $85 \%$. O material foi colocado para secar à temperatura ambiente. Uma mistura de ácido tioglicólico e ácido clorídrico $2 \mathrm{~N}(1: 10 \mathrm{v} / \mathrm{v})$ foram adicionados a essa amostra de tecido foliar e homogeneizada ( $5 \mathrm{~mL}$ para $15 \mathrm{mg}$ de tecidos), por $4 \mathrm{~h}$, a $100^{\circ} \mathrm{C}$. Após esse procedimento, realizou-se lavagem em água destilada e, em seguida, extraiu-se o ácido lignotioglicolítico a partir do precipitado com $5 \mathrm{~mL}$ de hidróxido de sódio $(\mathrm{NaOH} 0,5 \mathrm{~N})$, por $18 \mathrm{~h}$. As amostras foram então centrifugadas, acidificadas com $\mathrm{HCl}$ concentrado e incubadas, a $4^{\circ} \mathrm{C}$, por quatro horas. Em seguida, procedeu-se nova centrifugação e o precipitado foi ressuspenso em $\mathrm{NaOH}$ 0,5 $\mathrm{N}$ e a absorbância dessa solução foi determinada a $280 \mathrm{~nm}$ conforme Monties (21). O teor de lignina foi determinado (21) pela seguinte fórmula:

Lignina $=\mathrm{Abs}_{280 \mathrm{~nm}} * 144,93 *$ diluição $(8 \mathrm{~mL}) / 200(\mathrm{mg}$ de tf $)$

Abs = absorbância, $\mathrm{tf}=$ tecido foliar.

Após o término das avaliações, a parte aérea das plantas foi utilizada para análise nutricional. Para isso, as plantas foram lavadas em água destilada, acondicionadas separadamente em sacos de papel e secas em estufa, a $60^{\circ} \mathrm{C}$, até atingirem peso constante. Em seguida, procedeu-se à pesagem e à moagem da matéria seca da parte aérea das plantas. Os teores de macro, micronutrientes e silício foram determinados em cada amostra. Para silício utilizou-se método colorimétrico do "azul-de-molibdênio" proposto por Furlani \& Galo (8) e para nitrogênio, fósforo, potássio, cálcio, magnésio, enxofre, boro, cobre, ferro, zinco e manganês, seguiu-se metodologia descrita por Malavolta et al. (15).

A análise de variância do experimento foi realizada no programa SISVAR, versão 4.6 (Build 6.1) idealizado por Ferreira (7). As variáveis significativas no teste $\mathrm{F}$ foram submetidas ao ajuste de modelos de regressão. 


\section{RESULTADOS E DISCUSSÃO}

A temperatura média durante o período de condução do experimento foi de $23^{\circ} \mathrm{C}$, com média das máximas e mínimas de $31^{\circ} \mathrm{C} \mathrm{e}$ $18^{\circ} \mathrm{C}$, respectivamente. A faixa de temperatura considerada ideal para germinação máxima de urediniósporos encontra-se entre $15^{\circ} \mathrm{C}$ a $25^{\circ} \mathrm{C}$ (16). No entanto, P. pachyrhizi adapta-se à ampla variação de temperatura (19). Sendo assim, esse intervalo entre temperatura máxima e mínima e alta umidade do ar foi favorável ao patógeno.

Houve diferença significativa para a área abaixo da curva do número de lesões $/ \mathrm{cm}^{2}$ de área foliar (AACNL) em relação às doses de silício, com ajuste quadrático da equação de regressão. Com o aumento do silício na solução nutritiva observou-se redução na AACNL (Figura 1). As plantas supridas com $280 \mathrm{mg} / \mathrm{L}$ de silício, tiveram $24,3 \%$ menos AACNL em relação às plantas cultivadas sem a adição de silício. Da mesma forma, o silício contribuiu para a redução da intensidade de doenças em várias culturas. Pozza et al. (24) observaram redução de $63,2 \%$ de folhas de cafeeiro lesionadas por Cercospora coffeicola Berkeley \& Cooke, e de $43 \%$ no total de lesões por plantas com o emprego de $1 \mathrm{~g}$ de silicato de cálcio incorporado em $1 \mathrm{~kg}$ de substrato para tubetes. Plantas de soja cultivadas em solução nutritiva com 40 $\mathrm{mg} / \mathrm{L}$ de silício, apresentaram redução na intensidade do cancro da haste [Diaporthe phaseolorum (Cke \& Ell. Sacc.) var. meridionalis (Morgan-Jones)] reduzindo o número de lesões em até 90\% (12). Resultados promissores, no controle do oídio [Sphaerotheca fuliginea (Schlecht.:Fr) Poll.], foram encontrados em plantas de pepino (Cucumis sativus L.), cultivadas em solução nutritiva, suplementada com $100 \mathrm{mg} / \mathrm{L}$ de silicato de potássio (25). Esses autores observaram redução no crescimento das colônias de oídio nas folhas das plantas tratadas, atribuída a presença de silício ao redor das hifas. Folhas de videira infectadas com Uncinula necator (Schwein) Burril e pulverizadas com 17 mM (1000 mg/L) de silicato de potássio apresentaram 14\% menos colônias quando comparadas com plantas controle (4).

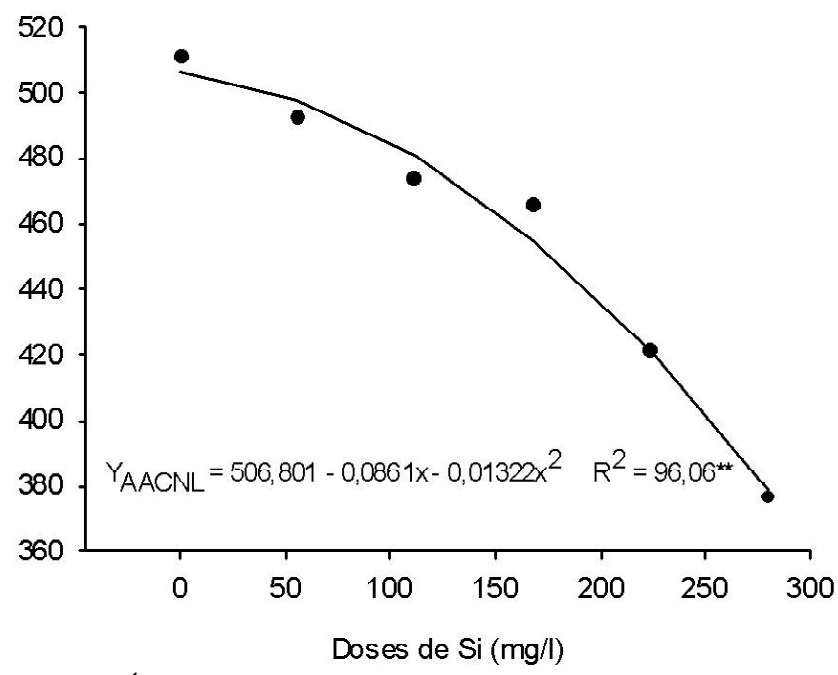

Figura 1. Área abaixo da curva de progresso do número de lesões de ferrugem (Phakopsora pachyrhizi)/ $\mathrm{cm}^{2}$ de área foliar (AACNL) de plantas de soja (Glycine max), em função de doses crescentes de silício em solução nutritiva.

O número de lesões $/ \mathrm{cm}^{2}$ de área foliar aumentou de forma linear a partir da segunda avaliação, sete dias após inoculação (7DAI), independente da dose de silício adicionada à solução. Porém, para doses de $224 \mathrm{mg} / \mathrm{L}$ e $280 \mathrm{mg} / \mathrm{L}$ de silício o número de lesões $/ \mathrm{cm}^{2}$ foi menor, comparado com as demais doses e a testemunha (Figura 2).
Como a ferrugem é uma doença policiclíca, o inóculo primário, originado de infecções iniciais aliado à temperatura e à umidade favoráveis contribuíram para o progresso da doença. Em trabalhos com diferentes cultivares de soja, Zambenedetti et al. (29) também verificaram aumento no número de lesões $/ \mathrm{cm}^{2}$ de área foliar a partir da segunda avaliação (5 dias após inoculação - DAI).

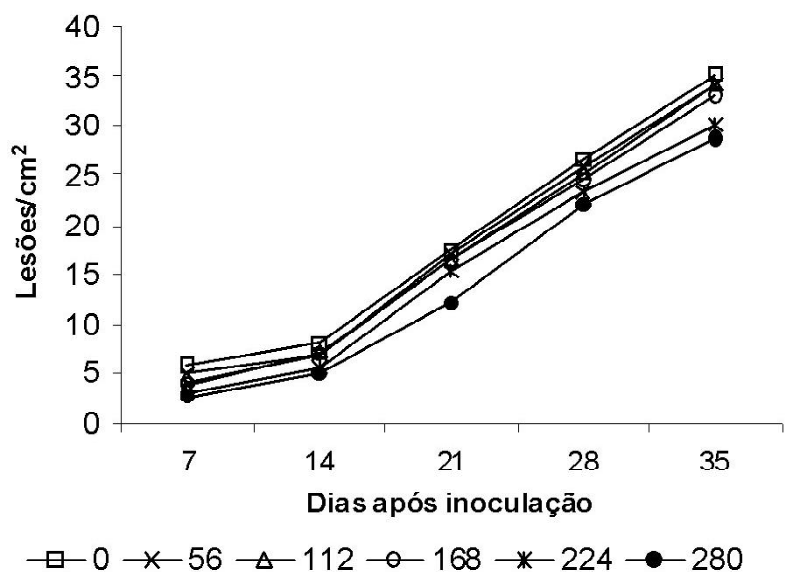

Figura 2. Curva de progresso do número de lesões $/ \mathrm{cm}^{2}$ de área foliar de plantas de soja (Glycine max), em função de dias após inoculação com ferrugem (Phakopsora pachyrhizi).

A clorofila $a$ não diferiu entre as doses de silício aplicadas. Com o aumento da concentração de silício em solução nutritiva, as quantidades de clorofila $b$ e de carotenóides aumentaram até as doses $140 \mathrm{mg} / \mathrm{L} \mathrm{e}$ $155 \mathrm{mg} / \mathrm{L}$ de silício, respectivamente, reduzindo em seguida (Figura 3D). Em diversos trabalhos com outras dicotiledôneas, também foi observado aumento no conteúdo de clorofila total, ou seja, $a+b$, nas folhas. Em plantas de pepino, cultivadas em solução nutritiva, com $46 \mathrm{mg} / \mathrm{L}$ de silício houve aumento da clorofila total (1). Provavelmente, esse aumento está relacionado à melhoria da arquitetura das plantas (14), devido ao menor ângulo foliar e consequentemente maior interceptação de luz e aumento na capacidade fotossintética (1).

As diferentes doses de silício, acrescidas à solução nutritiva, influenciaram significativamente o teor de lignina nas folhas (Figura 3C). Somente a partir da dose de $253 \mathrm{mg} / \mathrm{L}$ de silício observou-se redução nos teores de lignina, conforme o ponto de máximo obtido no ajuste quadrático da equação de regressão. Esses resultados foram semelhantes aos encontrados por Botelho et al. (3) em mudas de café tratadas com silicato de cálcio no solo e inoculadas com C. coffeicola. Nesse patossistema, verificou-se aumento do teor de lignina nas folhas até a dose de $0,52 \mathrm{~g} / \mathrm{kg}$ de $\mathrm{SiO}_{2}$ no substrato $(243 \mathrm{mg} / \mathrm{kg}$ de silício), reduzindo logo após essa dose, constituindo-se como barreira física à penetração do patógeno. Ainda, no presente experimento, a AACNL apresentou forte correlação negativa $(-0,82)$ com o teor de lignina nas folhas, ou seja, com aumento do teor de lignina houve redução na AACNL.

Segundo Bowen et al. (4) a redução da severidade do oídio da videira, também foi devido à formação de barreira física, dificultando a penetração das hifas. O silício pode favorecer o acúmulo de lignina, importante componente na resistência das plantas aos patógenos (14). Além da formação de barreira física, o silício pode ativar mecanismos de defesa da planta $(5,20)$. Cultivares de pepino cultivadas em solução nutritiva contendo silicato de potássio e inoculadas com $S$. fuliginea apresentaram maior atividade das enzimas peroxidases e polifenoloxidases, comparadas com plantas supridas com silício e não 
A

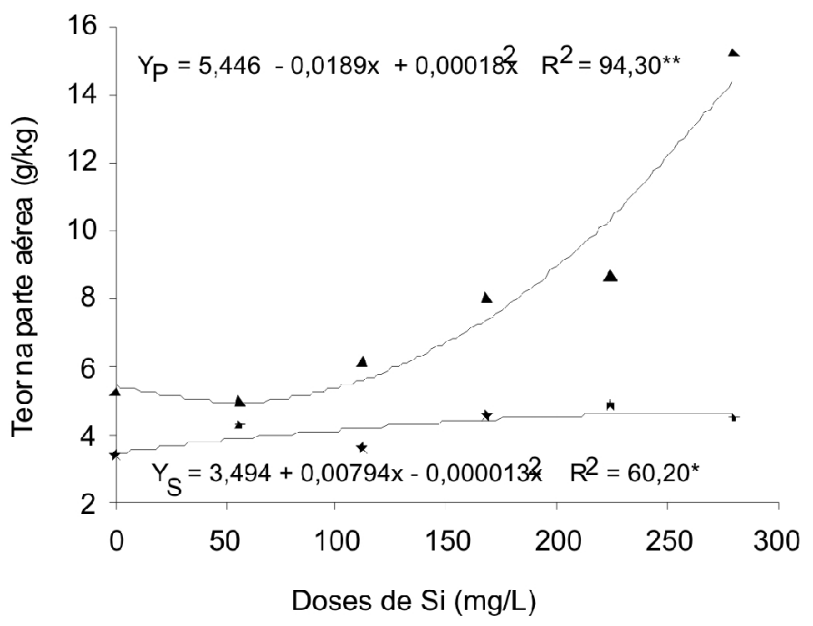

C

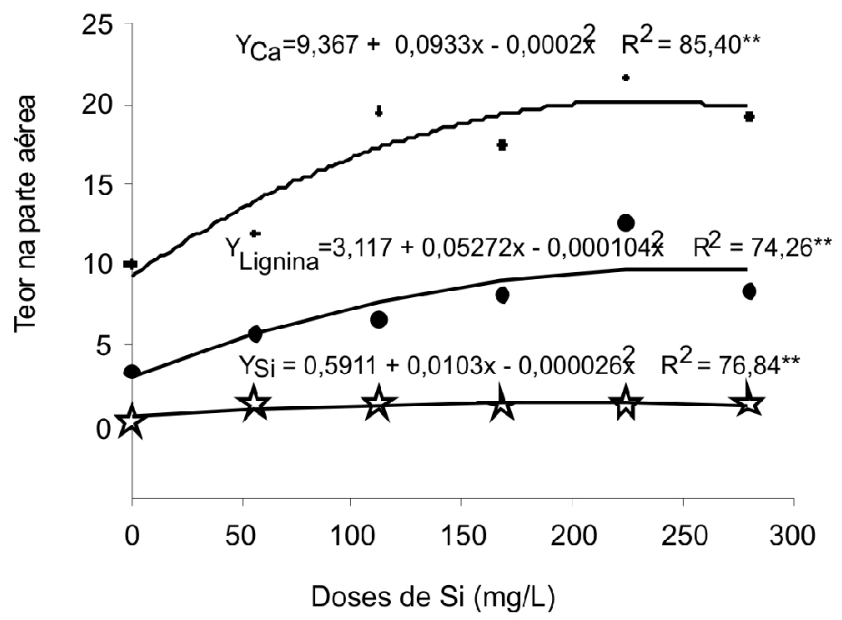

B

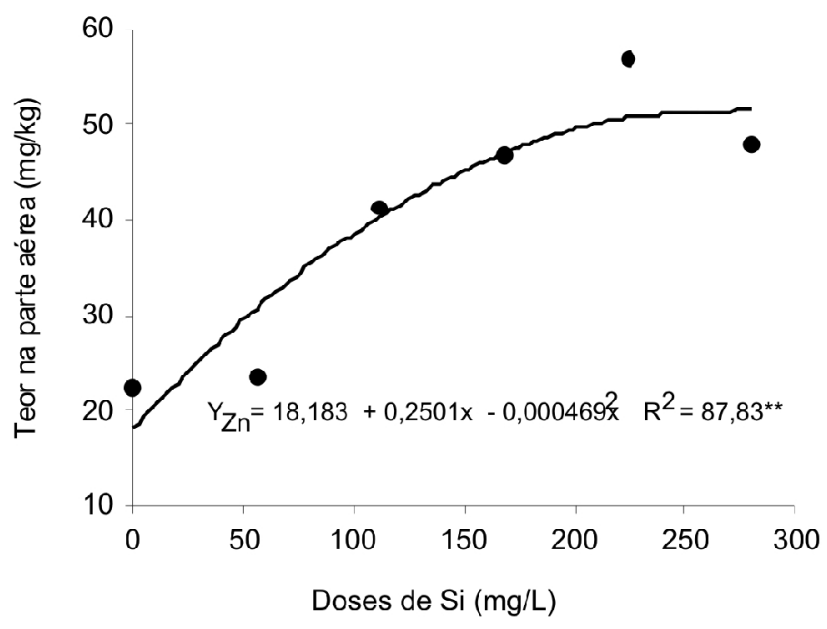

D

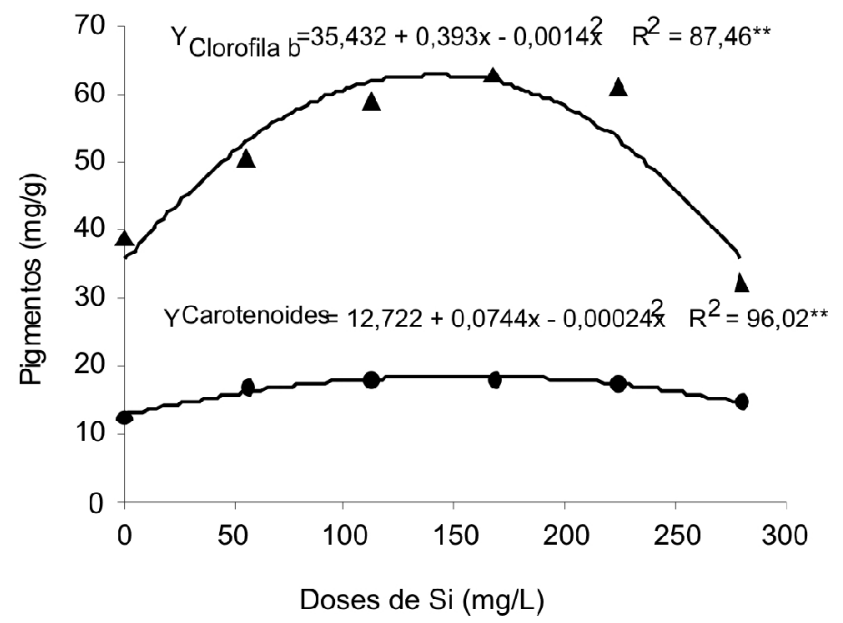

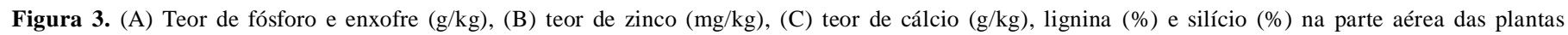

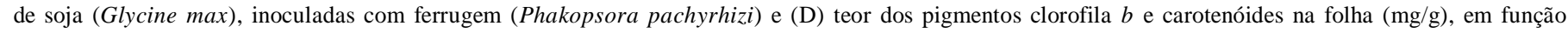
de doses crescentes de silício em solução nutritiva.

inoculadas com o patógeno (12). Segundo esses autores e também Marschner (17), essas enzimas são precursoras na biossíntese de lignina. Dessa forma, o aumento no teor de lignina observado nesse experimento favoreceu a redução da severidade da ferrugem da soja.

A nutrição das plantas de soja também sofreu influência do suprimento de silício na solução nutritiva. Observaram-se diferenças significativas para os teores de fósforo $(\mathrm{P})$, enxofre (S) (Figura 3A), zinco (Zn) (Figura 3B) e cálcio (Ca) (Figura 3C). Esses nutrientes aumentaram nas folhas de soja apenas com a adição do silício à solução nutritiva, mesmo não tendo sido adicionado, de forma diferenciada, nenhum deles na solução (Tabela 1). Entretanto, os teores dos demais macronutrientes (nitrogênio, potássio e magnésio) na parte aérea da soja não foram influenciados pelas doses de silício.

Os teores máximos e mínimos encontrados neste experimento encontram-se acima dos níveis considerados críticos para cultura da soja, somente o teor mínimo de nitrogênio encontrou-se dentro desse nível, o valor máximo foi maior (Tabela 2). Os níveis críticos encontrados por Urano et al. (27) do nitrogênio e do fósforo para soja, encontram-se abaixo dos valores encontrados nesse experimento, possivelmente por terem sido obtidos de plantas coletadas no campo.
Tabela 2. Teores máximos e mínimos de macronutrientes encontrados na parte aérea de plantas de soja (Glycine max) e níveis críticos (NC) destes nutrientes para cultura da soja.

\begin{tabular}{lcccccc}
\hline Teores e NC & $\mathbf{N}$ & $\mathbf{P}$ & $\mathbf{K}$ & $\mathbf{C ~ a}$ & $\mathbf{M g}$ & $\mathbf{S}$ \\
\hline & $\ldots \ldots \ldots \ldots \ldots \ldots \ldots \ldots \ldots \ldots \ldots \ldots . . \mathrm{g} / \mathrm{kg} \ldots \ldots \ldots \ldots \ldots \ldots \ldots \ldots \ldots \ldots \ldots \ldots \ldots \ldots \ldots \ldots \ldots \ldots \ldots \ldots \ldots \ldots \ldots \ldots \ldots \ldots \ldots \ldots \ldots \ldots$ \\
Máximo-Mínimo $^{1}$ & $57-61$ & $5-16$ & $19-27$ & $9-18$ & $3,9-5,3$ & $3,6-4,6$ \\
Nível crítico $^{2}$ & $29-57$ & $2-4$ & $13-29$ & $8-18$ & $1,8-5,0$ & $1,3-4,3$ \\
\hline
\end{tabular}

1.Teores máximo e mínimo) de nutrientes encontrados na parte aérea de plantas de soja em solução nutritiva com doses crescentes de silício.

2. Níveis críticos para cultura da soja com alta produtividade no campo segundo Urano et al. (26).

O silício também pode alterar o $\mathrm{pH}$ da rizosfera das plantas, influenciando dessa forma, a absorção de nutrientes essenciais para ativar mecanismos de defesa e barreiras estruturais (14). Além da ação antifúngica (17), os nutrientes podem atuar como co-fatores na síntese de enzimas, inclusive naquelas ligadas a patogênese tornando-se mais uma evidência da atuação dos nutrientes no processo de defesa da planta (23).

No solo, o ânion silicato disponibiliza o fosfato por substituição 
pelo mesmo sítio de adsorção ao colóide. Nesse experimento, observouse aumento na disponibilidade de fósforo com o suprimento de silício, mesmo em solução nutritiva, comprovado pela elevação do teor de fósforo na parte aérea das plantas de soja, sem que o mesmo tenha sido adicionado à solução (Figura 3A). Malavolta (14) sugere efeito sinergístico entre esses dois ânions. $\mathrm{O}$ aumento da resistência das plantas conferida pelo fósforo, segundo Marschner (17), relacionase com a função desempenhada por esse nutriente na planta destacando-se: fornecimento de energia armazenada em ATP, necessária para diversas funções na planta. Malavolta (14) complementa que o fósforo acelera a maturação de tecidos, permitindo o escape das plantas à infecção por patógenos.

O maior teor de cálcio nas folhas das plantas de soja supridas com maiores doses de silício pode ter contribuído para reduzir a severidade da doença. A presença desse nutriente na forma de pectatos de cálcio confere resistência à penetração de patógenos, por ser constituinte da lamela média e parede celular, além de atuar como mensageiro secundário importante na transdução de sinais para resposta de defesa das plantas contra patógenos (2).

De acordo com McGuire \& Kelman (18) o teor adequado de cálcio nos tecidos das plantas restringe a incidência de doenças por reduzir o efluxo de compostos de baixo peso molecular do citoplasma para o apoplasto e também por manter elevados os teores de poligalacturonatos de cálcio requeridos pela lamela média. Uma das formas utilizadas por muitos fitopatógenos para invadir tecidos vegetais consiste na produção de enzimas tais como poligalacturonases, as quais degradam a lamela média. Segundo Marschner (17), a atividade dessa enzima produzida pelo patógeno é inibida pela presença de cálcio nas plantas. Mudas de café, cultivadas em solução nutritiva também apresentaram redução na área abaixo da curva de progresso da incidência da cercosporiose com o aumento das doses de cálcio na solução nutritiva de 2 para 8 $\mathrm{mmol} / \mathrm{L}(9)$.

Observou-se efeito crescente do teor de zinco na parte aérea com o aumento da dose de silício na solução (Figura 3B). Para os demais micronutrientes ferro, cobre, manganês e boro, as doses de silício aplicadas não afetaram significativamente o teor foliar. A alteração do estado nutricional de plantas supridas com silício varia com a espécie. Para plantas de feijão, a adubação com silício via solo $(0 \mathrm{mg} / \mathrm{kg}, 466 \mathrm{mg} / \mathrm{kg}, 933 \mathrm{mg} / \mathrm{kg}$ e $1400 \mathrm{mg} / \mathrm{kg})$ como silicato de cálcio, também afetou a disponibilidade de cálcio, enxofre e zinco, não alterando os outros nutrientes (22). Em mudas de café adubadas com silicato de cálcio e sódio $(0 \mathrm{mg} / \mathrm{kg}$ de silício, $140 \mathrm{mg} /$ $\mathrm{kg}$ de silício, $280 \mathrm{mg} / \mathrm{kg}$ de silício e $560 \mathrm{mg} / \mathrm{kg}$ de silício), as concentrações de fósforo, potássio, enxofre, boro e zinco não foram influenciadas pelos tratamentos. No entanto, a aplicação de silício influenciou os teores de nitrogênio, cálcio e manganês (3). Todavia, as diferenças observadas nesse experimento para os teores de fósforo, cálcio e zinco foram de pequena magnitude, não justificando a redução da doença apenas por essa alteração.

$\mathrm{O}$ teor de silício na parte aérea das plantas de soja foi influenciado pelas doses de silício na solução nutritiva (Figura 3C). Houve aumento do teor de silício até a dose de $198 \mathrm{mg} / \mathrm{L}$ de silício na solução, reduzindo a seguir. $\mathrm{O}$ aumento de silício na parte aérea contribuiu para o aumento da resistência das plantas à ferrugem.

O mecanismo de ação do silício na redução desta doença ainda não é totalmente conhecido, mas, pode-se inferir que houve formação de barreira química devido à alteração no teor de lignina nas folhas. Ainda, no presente experimento, o suprimento de silício na solução nutritiva aumentou o teor de clorofila $b$, carotenóides, fósforo, cálcio, enxofre, zinco e silício na parte aérea das plantas de soja. Sendo assim, todas as variáveis analisadas estão envolvidas na redução do número de lesões da ferrugem da soja.

\section{AGRADECIMENTOS}

Agradecemos ao CNPq, a CAPES e a FAPEMIG pelo apoio financeiro.

\section{REFERÊNCIAS BIBLIOGRÁFICAS}

1. Adatia, M. H.; Besford, R. T. The effects of silicon in cucumber plants grown in recirculation nutrient solution. Annals of Botany, London, v.58, n.3, p. 343-351, 1986.

2. Agrios, G. N. Plant pathology. 5. ed. San. Diego: Academic Press, 2005. 922p.

3. Botelho, D. M. S.; Pozza, E. A.; Pozza, A. A. A.; Carvalho, J. G.; Botelho, C. E. Souza, P. E. Intensidade da Cercosporiose em mudas de cafeeiro em função de fontes e doses de silício. Fitopatologia Brasileira, Brasília, v.30, n.6, p.582-588, 2005.

4. Bowen, P.; Menzies, J. G.; Ehret, D. L.; Soluble silicon sprays inhibit powdery mildew development on grape leaves. Journal of the American Society Horticultural Science, Alexandria, v.117, n. 6, p. 906-912, 1992.

5. Chérif, M.; Asselin, A.; Bélanger, R. R. Defense responses induced by soluble silicon in cucumber roots infected by Pythium spp. Phytopathology, St. Paul, v. 84, n. 3, p. 236-242, 1994.

6. Datnoff, L. E.; Deren, C. W.; Snyder, G. H. Silicon fertilization for disease management of rice in Florida. Crop Protection, London, v.16, n. 6, p. 525-531,1997.

7. Ferreira, D. F. Programa estatístico SISVAR Versão 4.6 (Build 6.1). DEX/UFLA, Lavras, 2003. Disponível em: <http:// www.dex.ufla.br/danielff/dff02.htm>. Acesso em: 18 out. 2005.

8. Furlani, P. R.; Gallo, J. R. Determinação de silício em material vegetal, pelo método colorimétrico do "azul-de-molibdênio". Bragantia, Campinas, v. 37, n. 16, V-XI, 1978.

9. Garcia Júnior, D.; Pozza, E. A; Pozza, A. A. A.; Souza, P. E.; Carvalho, J. G.; Balieiro, A. C. Incidência e severidade da cercosporiose do cafeeiro em função do suprimento de potássio e cálcio em solução nutritiva. Fitopatologia Brasileira, Brasília, v.28, n. 3, p.286-291, 2003

10. Gong, H.; Zhu, X.; Chen, K.; Wang, S.; Zhang, C. C. Silicon alleviates oxidative damage of wheat plants in pots under drought. Plant Science, Clare, v.169, n.2, p.313-321, 2005.

11. Hoagland, D. R.; Arnon, D. I. The water culture method of growing plants without soil. Berkeley: University of Califórnia, 1950. 32p.

12. Liang, Y. C.; Sun, W. C.; SI, J.; ROMHELD, V. Effects of foliarand root-applied silicon on the enhancement of induced resistance to powdery mildew in Cucumis sativus. Plant Pathology, Oxford, v.54, n.5, p. 678-685, 2005.

13. Lima, M. T. G. Interrelação cancro da haste (Diaporthe phaseolorum f. sp. meridionalis), nodulação (Bradyrhizobium japonicum) e silício em soja [Glycine max (L.) Merril]. 1998. 58 p. Tese (Doutorado em Energia Nuclear na Agricultura) - Centro de Energia Nuclear na Agricultura, Piracicaba, SP.

14. Malavolta, E. Manual de nutrição mineral de plantas. $1^{a}$ edição. São Paulo: Agronômica Ceres. 2006. 638p.

15. Malavolta, E.; Vitti, G. C.; Oliveira, S. A. Avaliação do estado nutricional das plantas: princípios e aplicações. 2. ed. Piracicaba: POTAFOS. 1997. 319p.

16. Marchetti, M. A.; Melching, J. S.; Bromfield, K. R. The effects of temperature and dew period on germination and infection by uredospores of Phakopsora pachyrhizi. Phytopathology, St. Paul, v. 66, n. 4, p. 461-463, 1976.

17. Marschner, H. Mineral nutrition of higher plants. 2. ed. London: Academic Press. 1995. 889p.

18. McGuire, R. G.; Kelman, A. Calcium in potato tuber cell walls in 
relation to tissue maceration by Erwinia carotovora pv. Atroseptica. Phytopatology, St. Paul, v.76, p.401-406, 1986.

19. Melching, J. S. Effects of Duration, Frequency, and Temperature of Leaf Wetness Periods on Soybean Rust. Plant Disease, St. Paul, v. 73, n. 2, p. 117-122, 1989.

20. Menzies, J. G.; Ehret, D. L.; Glass, A. D. M.; Helmer, T.; Koch, C.; Seywerd, F. The influence of silicon on cytological interactions between Sphaerotheca fuliginea and Cucumis sativus. Physiology Molecular Plant Pathology, London, v.39, n. 6, p. 403 - 414,1991.

21. Monties, B. Lignins. In: Dey, P. M.; Harbone, J. B. Methods in plant biochemister. New York: Academic Press. 1989. p.113-158.

22. Moraes, S. R. G.; Pozza, E. A.; Alves, E.; Pozza, A. A. A.; Carvalho, J. C.; Lima. P. H.; Botelho, A. O. Efeito de fontes de silício na incidência e na severidade da antracnose do feijoeiro. Fitopatologia Brasileira, Brasília, v.31, n.1, p. 69-75, 2006.

23. Pozza, A. A. A.; Pozza, E.A.; Botelho, D.M.S. O silício no controle de doenças de plantas. Revisão anual de patologia de plantas, Passo Fundo, v. 12, p. 373-402, 2004a.

24. Pozza, A. A. A.; Alves, E.; Pozza, E. A.; Carvalho, J. G.; Montanari, M.; Guimarães, P. T. G.; Santos, D. M. Efeito do silício no controle da cercosporiose em três variedades de cafeeiro. Fitopatologia Brasileira, Brasília, v.29, n.2, p.185-188, 2004b.

25. Samuels, A. L.; Glass, A. D. M.; Ehret, D. L.; Menzies, J. G. Mobility and deposition of silicon in cucumber plants. Plant, Cell and Environment, Oxford, v. 14, n. 5, p. 485-492, 1991.

26. Shaner, G.; Finney, R. E. The effect of nitrogen fertilization on the expression of slow-mildewing resistance in knox wheat. Phytopathology, St. Paul, v.70, n. p.1183-1186, 1977.

27. Urano, E. O. M.; Kurihara, C. H.; Maeda, S.; Vitorino, C. T.; Gonçalves, M. C.; Marchetti, M. E. Avaliação do estado nutricional da soja. Pesquisa Agropecuária Brasileira, Brasília, v. 41, n.9, p.142-1428, 2006.

28. Wellburn, A. R. The spectral determination of chlorophylls a and b, as well as total carotenoids, using various solvents with spectrophotometers of different resolution. Journal of Plant Physiology, Jena, v. 144, n. 3, p.307-313, 1994.

29. Zambenedetti, E. B.; Alves, E.; Pozza, E. A.; Araújo, D. V.; Godoy, C, V. Avaliação de parâmetros monocíclicos e da intensidade da ferrugem asiática (Phakopsora pachyrhizi) em diferentes genótipos de soja e posições de copa. Summa Phytopathologica, Botucatu, v.33, n. 2, p. 178-181, 2007. 